\title{
Modelagem Interativa de um Processo de Desenvolvimento com Base na Percepção da Equipe: Um Relato de Experiência
}

\author{
Alternative Title: Interactive Process Modeling based on the Team Perception: An \\ Experience Report
}

\author{
Bruno S. Aragão \\ Grupo de Redes de \\ Computadores, Engenharia de \\ Software e Sistemas \\ Universidade Federal do \\ Ceará \\ Fortaleza, Ceará, Brasil \\ bruno@great.ufc.br
}

\author{
Ismayle S. Santos \\ Grupo de Redes de \\ Computadores, Engenharia de \\ Software e Sistemas \\ Universidade Federal do \\ Ceará \\ Fortaleza, Ceará, Brasil \\ ismaylesantos@great.ufc.br
}

\author{
Tales P. Nogueira \\ Grupo de Redes de \\ Computadores, Engenharia de \\ Software e Sistemas \\ Universidade Federal do \\ Ceará \\ Fortaleza, Ceará, Brasil \\ tales@great.ufc.br
}

\author{
Lana B. M. de Mesquita \\ Grupo de Redes de \\ Computadores, Engenharia de \\ Software e Sistemas \\ Universidade Federal do \\ Ceará \\ Fortaleza, Ceará, Brasil \\ lanamesquita@great.ufc.br
}

\author{
Rossana M. C. Andrade \\ Grupo de Redes de \\ Computadores, Engenharia de \\ Software e Sistemas \\ Universidade Federal do \\ Ceará \\ Fortaleza, Ceará, Brasil \\ rossana@great.ufc.br
}

\begin{abstract}
RESUMO
A modelagem do processo de desenvolvimento de software é importante para permitir um melhor entendimento desse processo, bem como a identificação de possíveis melhorias. Em um projeto de P\&D\&I, realizado em parceria entre um grupo de pesquisa de uma universidade federal brasileira e uma fabricante de celulares, uma melhoria do processo de desenvolvimento de software distanciou a versão do processo documentada da versão usada na prática. Para sincronizar essa documentação com o processo que estava sendo utilizado, aplicou-se uma abordagem interativa com base na observação das atividades conduzidas no projeto, na análise de documentos existentes, em reuniões com o gerente do projeto e em entrevistas com o time de desenvolvimento. Este artigo apresenta um relato da experiência do uso desta abordagem, descrevendo as lições aprendidas e a percepção da equipe quanto ao processo utilizado.
\end{abstract}

\section{Palavras-Chave}

modelagem de processo, pesquisa qualitativa, processo de desenvolvimento de software

Permission to make digital or hard copies of all or part of this work for personal or classroom use is granted without fee provided that copies are not made or distributed for profit or commercial advantage and that copies bear this notice and the full citation on the first page. To copy otherwise, or republish, to post on servers or to redistribute to lists, requires prior specific permission and/or a fee.

SBSI 2017 June $5^{\text {th }}-8^{\text {th }}, 2017$, Lavras, Minas Gerais, Brazil

Copyright SBC 2017.

\begin{abstract}
Modeling a software development process is important as it allows a better understanding of this process, as well as the identification of possible enhancements. In a research, development, and innovation project developed in partnership between a research group of a brazilian university and a mobile phone manufacturer, some changes in the development process resulted in an outdated process documentation. In order to update the documentation to reflect the process that was being used, an interactive approach was implemented. This approach was based on observations of project activities, document analysis, meetings with the project manager, and interviews with the development team. This paper presents an experience report about the application of this approach, describes the lessons learnt, and the team's perception regarding the process.
\end{abstract}

\section{CCS Concepts}

-Software and its engineering $\rightarrow$ Software development process management; •General and reference $\rightarrow$ Empirical studies;

\section{Keywords}

process modeling, qualitative research, software development process

\section{INTRODUÇÃO}

Para que um sistema de informação seja desenvolvido de forma consistente, é preciso aliar boas práticas da engenharia 
de software com um robusto e eficiente processo de desenvolvimento [19]. Um processo de desenvolvimento de software consiste em um conjunto de políticas, estruturas organizacionais, tecnologias, procedimentos e artefatos necessários para conceber, desenvolver, construir e manter um produto de software [8].

Ter processos bem definidos também está ligado à motivação da equipe de desenvolvimento [23]. Dessa forma, seguir um processo de software é um fator essencial para entregar software de qualidade [1]. Contudo, vale ressaltar que esse processo não é rígido e deve ser ágil e adaptável ao problema, à equipe, ao projeto e à cultura organizacional [14]. Assim, é comum presenciar projetos que estabeleçam processos de software que se alteram após algum tempo devido a melhorias internas ou mesmo após uma mudança no projeto, como, por exemplo, a inclusão de novos integrantes.

O relato aqui apresentado foi realizado no Grupo de Redes de Computadores, Engenharia de Software e Sistemas (GREat) da Universidade Federal do Ceará (UFC), onde são realizados projetos de pesquisa, desenvolvimento e inovação por meio da Lei de Informática ${ }^{1}$ do Ministério da Ciência, Tecnologia e Inovação ${ }^{2}$ (MCTI) em parceria com empresas privadas. Um destes projetos é voltado para dispositivos móveis e envolve customizações de software embarcado para celular. Neste projeto, assim como mencionado acima, mudanças e melhorias internas provocaram alterações no processo de desenvolvimento utilizado.

Anteriormente, o projeto em questão utilizava um processo baseado nas técnicas do Scrum [16] e Kanban [21] aliado à uma metodologia de avaliação do Scrum desenvolvida durante o projeto. Em trabalhos anteriores foram apresentados um processo para este projeto que mesclava o Scrum e o Kanban [20] e uma metodologia de avaliação do Scrum utilizada [4]. No último ano, no entanto, mudanças no projeto afetaram as atividades que estavam sendo realizadas e o projeto se distanciou do processo previamente definido. Assim, surgiu a necessidade de se fazer uma análise e documentação da nova versão do processo que estava em execução.

Para garantir que o processo modelado fosse fiel às atividades em execução, conduziu-se uma abordagem de modelagem de processo com base na análise de documentos existentes, observações das atividades e processos executados pela equipe. Além disso, foram realizadas entrevistas para coletar feedback da equipe sobre o trabalho realizado no dia a dia. Dessa forma, o processo foi modelado de forma interativa a partir das informações que iam sendo coletadas. Vale ressaltar que a técnica de realização de entrevistas foi escolhida, pois ela permite coletar dados descritivos na linguagem do entrevistado [3], possibilitando ao entrevistador desenvolver intuitivamente uma ideia sobre a maneira como os participantes interpretam aspectos do trabalho.

O presente artigo apresenta o relato dessa experiência na modelagem de um processo de desenvolvimento de software, que foi feita de forma interativa e envolvendo todos da equipe de desenvolvimento. Os resultados desse relato podem ser utilizados tanto por outras equipes de desenvolvimento de software para guiar a modelagem do processo utilizado, quanto por pesquisadores interessados em investigar experiências da indústria na modelagem de processos de desenvolvimento de software.

\footnotetext{
${ }^{1}$ Leis 8.248/91, 10.176/01 e $11.077 / 04$

${ }^{2}$ http://www.mcti.gov.br/
}

O restante deste artigo está organizado em mais cinco seções. Na Seção 2 são apresentados os trabalhos relacionados. Na Seção 3 são descritos o ambiente do relato e a metodologia de pesquisa utilizada. Na Seção 4 são discutidos os resultados obtidos. Na Seção 5 são apresentadas as lições aprendidas durante a experiência descrita neste artigo. Por fim, as conclusões são apresentadas na Seção 6.

\section{TRABALHOS RELACIONADOS}

Fazendo uma pesquisa na literatura, é possível encontrar diversos trabalhos que propõem abordagens para apoiar a modelagem de um processo de software.

Alguns desses trabalhos focam apenas na técnica de modelagem utilizada. Por exemplo, o trabalho de Kozusznik e Stolfa [9] propõe uma técnica de modelagem de processo de software baseada em ontologias. Já o trabalho de Diebold e Scherr [7] investiga, por meio de entrevistas, o quanto a descrição dos processos de software é feita na prática usando notações formais ou descrições semi-formais. O diferencial deste artigo para os trabalhos de Kozusznik e Stolfa [9] e Diebold e Scherr [7] é que este relato não foca em uma notação de modelagem, mas sim em apresentar a experiência durante a atividade de modelagem de processo de software.

Outros trabalhos da literatura focam em coletar a experiência da equipe quanto ao processo utilizado. Esses, são interessantes porque um dos primeiros passos para identificar melhorias no processo de software é entender como o processo de desenvolvimento é percebido pela equipe.

Thiry et.al. [22] apresentam uma abordagem colaborativa que promove a discussão entre os envolvidos para a modelagem e validação do processo de software por meio de oficinas. Assim, a proposta do artigo de Thiry et.al. [22] envolve a modelagem de processos de forma incremental a partir de reuniões com a participação de envolvidos representando diferentes papéis nestes processos. O relato deste artigo também trata de uma modelagem colaborativa, i.e., com a participação dos envolvidos. Contudo, ao contrário do trabalho de Thiry et.al. [22] que coletou o feedback por meio de oficinas, neste artigo a coleta do feedback da equipe foi feita por meio de entrevistas individuais, permitindo que cada membro expressasse sua percepção do processo sem a influência de outros membros.

Dias Júnior et. al. [5] apresentam um estudo de caso sobre as percepções de duas equipes com o objetivo de verificar se o processo de software era compreensível, útil, importante e utilizado adequadamente sob o ponto de vista das equipes de desenvolvimento. Em um outro trabalho, Dias Júnior et. al. [6] apresentam os resultados de um estudo de caso que analisou as percepções de uma equipe em relação aos resultados esperados do processo de Gerência de Configuração do MPS.BR Nível F [18] e verificaram se estas percepções refletiam os resultados das auditorias realizadas. Em ambos os trabalhos de Dias Júnior et. al. foram coletados dados através de entrevistas, observação e análise documental, mesma metodologia seguida pelo presente trabalho. Entretanto, a experiência descrita neste artigo foca no uso dessas abordagens durante a modelagem do processo, enquanto que Dias Júnior et. al. focam em capturar a percepção da equipe quanto ao processo em uso.

Finalmente, Xavier et. al. [23] entrevistaram membros de times de desenvolvimento para analisar a influência do processo de software na motivação de equipes de duas organizações distintas. Este artigo não investiga a motivação 
das equipes de desenvolvimento, mas o uso da percepção da equipe quanto ao processo utilizado no dia a dia para guiar a atividade de modelagem de processo de software.

\section{METODOLOGIA}

Quanto à abordagem metodológica utilizada, pode-se classificar esta pesquisa como descritiva [10], pois a finalidade foi observar, registrar e analisar as experiências durante a modelagem de um processo de desenvolvimento de software. Quanto ao procedimento metodológico, esta pesquisa pode ser classificada como qualitativa [10], pois ela descreve a experiência relacionada à modelagem interativa com base na percepção da equipe (coletada por meio de entrevistas) quanto ao processo. Nas próximas subseções são apresentados o projeto em que ocorreu a experiência, a abordagem de modelagem interativa utilizada, detalhes sobre a organização das entrevistas, e a análise e interpretação dos dados.

\subsection{Ambiente da Experiência}

Esta pesquisa foi realizada dentro de um projeto que desenvolve customizações de software embarcado para modelos de celular com a finalidade de atender as especificações de interface com o usuário, as funcionalidades e as configurações solicitadas pelas operadoras de celular.

O projeto era composto por dezesseis integrantes: um gerente de projeto, quatro líderes técnicos, um líder de projeto, três analistas de testes e sete analistas de sistemas. Esses últimos também faziam testes de acordo com a demanda.

O gerente de projeto tinha o papel de manter o processo de desenvolvimento de software para que a equipe pudesse realizar as atividades necessárias no tempo previsto e para que o resultado tivesse a qualidade esperada. O líder técnico possuía conhecimentos técnicos específicos, cabendo a ele gerenciar um time para realizar atividades relacionadas ao modelo de dispositivo móvel pelo qual ele era responsável. O líder de projeto gerenciava o cronograma do projeto, analisava os riscos, controlava a qualidade, alocava recursos e era quem ficava em contato com a parceira.

Além disso, cabe ressaltar que o projeto era formado por quatro times: Analistas de Sistemas, que realizavam o desenvolvimento, Testadores de Compatibilidade, que realizavam testes de compatibilidade, Analistas de Testes, que realizavam testes em geral e Integradores, que executavam tanto as atividades de integração quanto as de gerência de configuração. Os líderes técnicos podiam estar presentes em um ou mais times, assim como um time poderia conter mais de um líder técnico.

A Figura 1 apresenta a organização da equipe de acordo com seus cargos e seus times. Os círculos que representam os times das equipes são proporcionais à quantidade de pessoas envolvidas. Os círculos de gerente e líderes representam uma única pessoa.

\subsection{Modelagem Interativa do Processo}

A Figura 2 apresenta as etapas, em notação BPMN (Business Process Model and Notation), da abordagem utilizada para modelagem interativa do processo.

A definição do processo se iniciou com base na observação e análise de documentos existentes, como apresentações de slides com resultados anuais do projeto, documentos sobre o processo adotado anteriormente [20], ferramentas que eram usadas e atividades que foram executadas. Todos esses documentos estavam disponíveis na plataforma de documentação

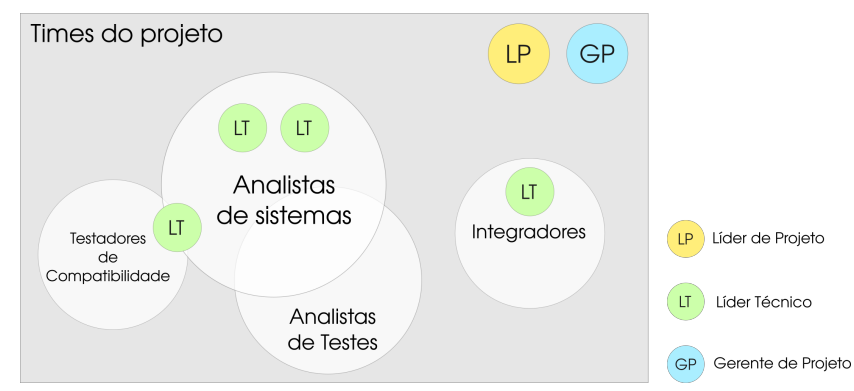

Figura 1: Visão geral dos papéis dentro da equipe

colaborativa utilizada no projeto ${ }^{3}$. É importante ressaltar que um dos autores trabalhou no projeto por dois anos, o que permitiu uma observação das atividades estando inserido no contexto do projeto, facilitando assim o entendimento do processo e suas particularidades.

Em um segundo momento, foi gerada a versão 1 do processo a partir de reuniões entre os pesquisadores e o gerente do projeto. Em seguida, foram realizadas entrevistas com os integrantes da equipe, separada em dois grupos. Essas entrevistas foram realizadas em dois dias consecutivos e de acordo com a disponibilidade dos integrantes. Ao final do primeiro dia de entrevistas, que contou com seis entrevistados, uma segunda versão do modelo do processo foi criada. Essa versão do processo já incorporava algumas das sugestões dos entrevistados do primeiro dia. No segundo dia de entrevistas, realizado com quatro entrevistados, foram apresentadas as versões 1 e 2 do processo para que cada entrevistado confrontasse as modificações sugeridas no primeiro dia de entrevistas. Por fim, após todas as entrevistas os resultados foram consolidados e gerou-se a versão 3 do processo, que foi o resultado final da atividade de modelagem.

Com relação ao tipo de entrevista, seguiu-se um formato semiestruturado, no qual roteiros são compostos de tópicos ou perguntas (geralmente abertas) que devem ser endereçadas na entrevista em uma ordem lógica [2]. Mais detalhes das entrevistas são apresentados na seção 3.2.1. Cabe ainda ressaltar que a pesquisa contou com o apoio do gerente e dos líderes. Assim, todas as entrevistas foram realizadas no local de trabalho e durante o horário de expediente.

\subsubsection{Organização das Entrevistas}

No início de cada entrevista, cada entrevistado recebia um termo de consentimento no qual o participante indicava concordar com a entrevista. Esse termo também deixava claro que as entrevistas seriam gravadas e que incumbia aos pesquisadores o sigilo dos dados adquiridos. Nesse momento, os pesquisadores explicavam os objetivos da pesquisa com as entrevistas. Depois que os entrevistados aceitavam os termos da entrevista, a mesma era iniciada. Não foi definido um tempo limite para as entrevistas para não inibir o entrevistado durante a atividade.

As entrevistas foram organizadas de forma a abranger questões técnicas relacionadas ao processo e à percepção da equipe com relação ao processo. Para isto, os pesquisadores envolvidos determinaram um roteiro de entrevista que foi organizado em quatro partes, a saber: identificação do usuário, análise do processo modelado, questionamentos sobre o processo, e desaquecimento. A Tabela 1 apresenta

\footnotetext{
${ }^{3}$ https://br.atlassian.com/software/confluence
} 


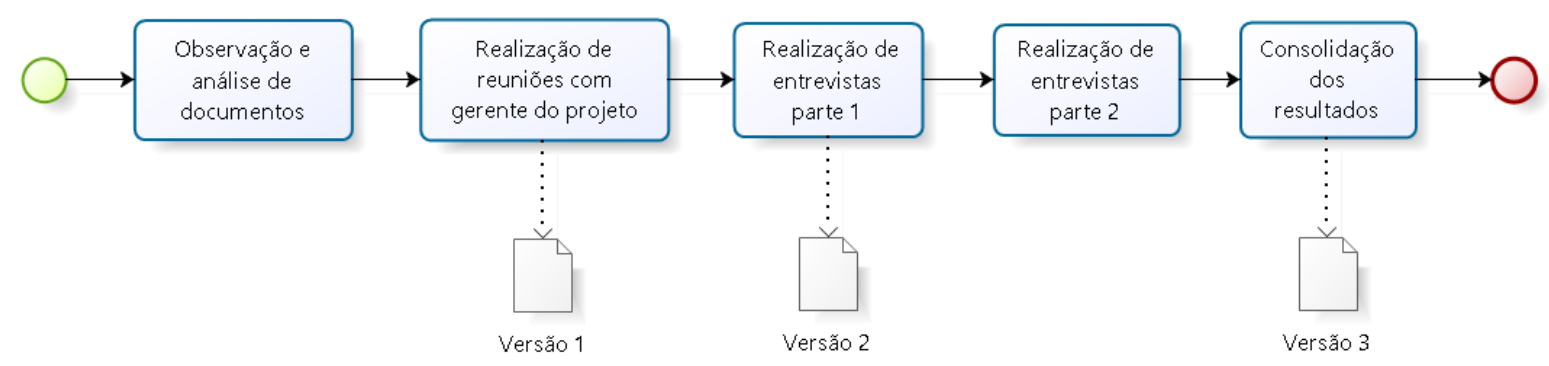

Figura 2: Etapas da abordagem de modelagem

as partes do roteiro, as categorias, os tópicos que levaram às perguntas ou às explicações no momento da entrevista $\mathrm{e}$ alguns exemplos de perguntas utilizadas nas entrevistas.

Na parte de identificação do usuário foram realizadas questões sobre o perfil do entrevistado (e.g. formação acadêmica) e sua experiência no projeto (e.g. tempo na equipe). $\mathrm{Na}$ parte de análise do processo modelado, foi exposto ao entrevistado a versão mais recente do processo no momento da entrevista e foi pedido que ele propusesse modificações enquanto tecia comentários. No primeiro dia de entrevistas, os entrevistados receberam impressa a versão 1 do processo. Já no segundo dia, o entrevistado recebia as versões 1 e 2 do processo e era questionado se concordava com as modificações aplicadas entre as duas versões. Em ambos os casos, o entrevistado poderia sugerir modificações no processo em cima da versão impressa. São exemplos de modificações: alterar os termos utilizados; modificar os fluxos de atividades; e adicionar novas atividades ao processo.

$\mathrm{Na}$ parte de questionamento sobre o processo, as questões foram abertas e o entrevistado respondia às perguntas de forma livre sobre quatro categorias: (i) utilização do processo, (ii) documentação, (iii) ferramentas, e (iv) natureza do projeto. Na parte de desaquecimento, os pesquisadores agradeceram à participação do entrevistado e perguntaram se haviam comentários adicionais úteis à pesquisa. Nessa parte, foram sanadas quaisquer dúvidas sobre a pesquisa e a entrevista com o objetivo de deixá-los confortáveis e confiantes com os resultados da entrevista.

Os dados extraídos das entrevistas foram as transcrições textuais das entrevistas e a modelagem do processo de software com as modificações sugeridas pelos entrevistados.

\subsubsection{Análise e interpretação dos dados da entre- vista}

A análise e a interpretação das entrevistas ocorreu de forma qualitativa e quantitativa de acordo com os tipos de respostas predominantes para cada tópico abordado nas entrevistas. Dentro do escopo semiestruturado, foram realizadas algumas perguntas objetivas (e.g. "A equipe utilizou este processo corretamente?" da categoria "Utilização correta do processo"). Essas perguntas foram respondidas com sim ou não e podiam ser seguidas de sua justificativa ou de algum comentário que acontecia espontaneamente por parte do entrevistado. Logo, foram gerados dados tanto quantitativos quanto qualitativos.

Para a análise qualitativa, utilizou-se a análise de conteúdo, uma técnica de investigação que tem por finalidade a descrição objetiva, sistemática e quantitativa do conteúdo manifesto da comunicação [17]. Com este objetivo, a técnica de categorização de dados [12] foi utilizada. Essa técnica se propõe a analisar o que é explícito no texto para obtenção de dados que permitam fazer inferências, além de buscar a presença ou a ausência de uma ou várias características. Outros trabalhos que analisam dados de entrevistas semiestruturadas também costumam utilizar esta técnica [13].

No âmbito das entrevistas, as partes textuais das transcrições foram organizadas em categorias que nortearam a consolidação dos dados e foram importantes para atingir os objetivos da pesquisa. Essa análise foi utilizada, por exemplo, para categorizar os benefícios de se ter um processo bem definido e documentado e encontrar os benefícios mais relevantes. Essa etapa foi realizada por dois avaliadores, aumentando a confiabilidade dos dados interpretados e dos resultados da pesquisa.

A técnica de identificação de padrões recorrentes ou temas [15], que agrupa as respostas com o objetivo de encontrar padrões, foi utilizada para auxiliar a análise qualitativa dos dados. De acordo com Miles et.al. [11], padrões recorrentes ou temas são capturados a partir da observação de fenômenos recorrentes nos dados. É possível utilizar essa técnica em conjunto com a categorização de dados para identificar padrões recorrentes nos dados colhidos. Neste artigo, foram utilizadas ambas as abordagens para, por exemplo, identificar as ferramentas mais usadas e os problemas mais citados com relação ao uso de ferramentas.

\section{RESULTADOS}

Na modelagem interativa, um esboço do processo foi gerado a partir da observação e análise de documentos. Contudo, percebeu-se que este esboço apresentava atividades que não condiziam com o processo real. Então, buscou-se realizar reuniões com o gerente do projeto a fim de definir a primeira versão do processo e melhorar a compreensão dos pesquisadores sobre o mesmo. Essa etapa durou aproximadamente dois meses.

A primeira versão, no entanto, não possuía todas as atividades e não deixava clara a divisão de atividades pelos diferentes times que compõem a equipe. Assim, para evoluir o modelo do processo levando em consideração a percepção da equipe, foram realizadas dez entrevistas que envolveram pessoas de todos os cargos. Essas entrevistas ocorreram durante dois dias, sendo divididas em duas etapas na modelagem interativa. Na primeira parte das entrevistas, gerou-se uma segunda versão do processo e, após a análise dos dados da segunda parte da entrevista, gerou-se a versão 3 do processo de desenvolvimento de software. 
Tabela 1: Roteiro de entrevista

\begin{tabular}{|c|c|c|c|}
\hline Etapa da entrevista & Categoria & Tópico & Exemplos de perguntas \\
\hline \multirow{5}{*}{ 1. Identificação do entrevistado } & \multirow[t]{5}{*}{$x_{1}+1$} & Idade & Qual sua idade? \\
\hline & & Formação acadêmica & Qual sua formação acadêmica? \\
\hline & & Profissão exercida na equipe & Qual seu papel no time? \\
\hline & & Tempo na equipe & $\begin{array}{l}\text { Há quanto tempo você trabalha na } \\
\text { equipe? }\end{array}$ \\
\hline & & Atividades realizadas no projeto & $\begin{array}{l}\text { Quais atividades você realizava no } \\
\text { projeto? }\end{array}$ \\
\hline 2. Análise do processo modelado & - & $\begin{array}{l}\text { Considerações sobre a modelagem do } \\
\text { processo }\end{array}$ & $\begin{array}{l}\text { O processo modelado corresponde } \\
\text { com o processo executado? }\end{array}$ \\
\hline \multirow{11}{*}{ 3. Questionamentos sobre o processo } & \multirow[t]{2}{*}{ Utilização do Processo } & Utilização correta do processo & $\begin{array}{l}\text { A equipe utilizou este processo cor- } \\
\text { retamente? }\end{array}$ \\
\hline & & $\begin{array}{l}\text { Benefícios em utilizar um processo } \\
\text { bem definido }\end{array}$ & $\begin{array}{l}\text { Quais os benefícios de utilizar um } \\
\text { processo bem definido? }\end{array}$ \\
\hline & \multirow{4}{*}{ Documentação } & $\begin{array}{l}\text { Visibilidade da documentação de } \\
\text { processo }\end{array}$ & $\begin{array}{l}\text { O processo está documentado e aces- } \\
\text { sível à todos? }\end{array}$ \\
\hline & & Utilização da documentação & A equipe utilizava a documentação? \\
\hline & & Importância da documentação & $\begin{array}{l}\text { Julga documentação importante } \\
\text { para o projeto? }\end{array}$ \\
\hline & & $\begin{array}{l}\text { Forma de aprendizado do processo } \\
\text { (documentação ou prática) }\end{array}$ & Como você aprendeu o processo? \\
\hline & \multirow[t]{4}{*}{ Ferramentas } & $\begin{array}{l}\text { Ferramentas utilizadas para ajudar } \\
\text { no processo (organização de tempo, } \\
\text { atividades ou comunicação) }\end{array}$ & $\begin{array}{l}\text { Quais ferramentas vocês utilizam } \\
\text { para organização das atividades? }\end{array}$ \\
\hline & & Correta utilização das ferramentas & A equipe utiliza bem as ferramentas? \\
\hline & & $\begin{array}{l}\text { Benefícios em utilizar corretamente } \\
\text { as ferramentas }\end{array}$ & $\begin{array}{l}\text { Quais os benefícios de utilizar estas } \\
\text { ferramentas? }\end{array}$ \\
\hline & & $\begin{array}{l}\text { Satisfação em utilizar as ferramentas } \\
\text { citadas }\end{array}$ & $\begin{array}{l}\text { Vocês se sente confortável em utili- } \\
\text { zar estas ferramentas? }\end{array}$ \\
\hline & Natureza do projeto & $\begin{array}{l}\text { Discussão sobre a natureza do pro- } \\
\text { jeto }\end{array}$ & $\begin{array}{l}\text { Qual a natureza do projeto? } \\
\text { É um projeto de desenvolvimento? }\end{array}$ \\
\hline 4. Desaquecimento & - & Considerações finais & - \\
\hline
\end{tabular}

Tabela 2: Entrevistados na pesquisa

\begin{tabular}{|c|c|c|c|}
\hline Entrevistado & $\begin{array}{l}\text { Tempo no } \\
\text { projeto }\end{array}$ & Cargo & $\begin{array}{l}\text { Tempo na } \\
\text { entrevista }\end{array}$ \\
\hline E1 & $\begin{array}{l}2 \text { anos e } 11 \\
\text { meses }\end{array}$ & $\begin{array}{l}\text { Gerente de } \\
\text { Configuração }\end{array}$ & $34 \mathrm{~m} 21 \mathrm{~s}$ \\
\hline E2 & 6 anos e 6 mese & Líder Técnico & $12 \mathrm{~m} 38 \mathrm{~s}$ \\
\hline E3 & 3 anos & $\begin{array}{l}\text { Líder de Pro- } \\
\text { jeto }\end{array}$ & $23 \mathrm{~m} 20 \mathrm{~s}$ \\
\hline $\mathrm{E} 4$ & 1 ano e 2 mese & $\begin{array}{ll}\text { Analista } & \text { de } \\
\text { teste }\end{array}$ & $18 \mathrm{~m} 28 \mathrm{~s}$ \\
\hline E5 & 2 anos & $\begin{array}{l}\text { Gerente de } \\
\text { Configuração }\end{array}$ & $17 \mathrm{m05s}$ \\
\hline E6 & 7 anos & Líder Técnico & $21 \mathrm{~m} 24 \mathrm{~s}$ \\
\hline E7 & 3 anos & Líder Técnico & $01 \mathrm{~h} 06 \mathrm{~m} 55 \mathrm{~s}$ \\
\hline E8 & $\begin{array}{l}1 \text { ano e } 4 \text { me- } \\
\text { ses }\end{array}$ & $\begin{array}{ll}\text { Gerente } & \text { de } \\
\text { projeto } & \end{array}$ & $57 \mathrm{~m} 33 \mathrm{~s}$ \\
\hline E9 & $\begin{array}{l}2 \text { anos e } 5 \text { me- } \\
\text { ses }\end{array}$ & $\begin{array}{ll}\text { Analista } & \text { de } \\
\text { Sistemas } & \\
\end{array}$ & $49 \mathrm{~m} 40 \mathrm{~s}$ \\
\hline E10 & $\begin{array}{l}2 \text { anos e } 6 \text { me- } \\
\text { ses }\end{array}$ & $\begin{array}{ll}\text { Analista } & \text { de } \\
\text { Sistemas } & \end{array}$ & $25 \mathrm{~m} 56 \mathrm{~s}$ \\
\hline
\end{tabular}

As entrevistas foram gravadas e totalizaram 5 horas e 27 minutos de gravação. O tempo de cada entrevista variou de 12 minutos a mais de uma hora. Cada entrevista foi transcrita por inteiro, exigindo, aproximadamente, 15 horas para realizar todas as transcrições. A Tabela 2 apresenta um sumário das entrevistas realizadas com o tempo de projeto dos entrevistados, o cargo que eles ocupam na equipe, e o tempo de duração de cada entrevista.

Outros dados foram colhidos na entrevista sobre o perfil do entrevistado. O perfil do grupo de entrevistados pode ser definido como pessoas de 25 a 42 anos, com uma média de 29 anos. Todos possuem formação superior na área de Ciências da Computação, e o grupo que participou das entrevistas era composto por um gerente de projeto, três líderes técnicos, um líder de projeto, dois gerentes de configuração e três testadores, dos quais dois eram também desenvolvedores.
A Tabela 2 indica, como esperado, que não há relação entre a média de tempo no projeto e o tempo da entrevista. A entrevista de maior duração foi com um dos líderes técnicos (E7). Por outro lado, a entrevista com os demais líderes, que esperava-se ter longa duração, teve duração abaixo da média. Acredita-se que isso foi influenciado pela personalidade introspectiva dos líderes técnicos.

Nas próximas subseções são apresentas a versão do processo resultante da análise das entrevistas, bem como outros resultados identificados com bases nas respostas obtidas durante as entrevistas.

\subsection{Versão Final do Processo}

A Figura 3 apresenta a modelagem final do processo em notação BPMN. Vale ressaltar que, por questões de confidencialidade, o modelo aqui apresentado foi reduzido para preservar componentes sensíveis ao projeto, mas que não são essenciais para a compreensão geral do fluxo de trabalho. Cada etapa deste processo é realizada por um time específico. As etapas são realizadas em sequência, com retornos à etapas anteriores somente para correções de falhas.

O processo modelado contempla um ciclo do software que pode ser o ciclo inicial, onde não há bugs (falhas em um sistema que provocam mau funcionamento), ou os ciclos seguintes, onde é necessário tanto corrigir bugs quanto desenvolver o software. Após a etapa de desenvolvimento, ocorre a etapa de integração, no qual são integradas as modificações realizadas no desenvolvimento e outras modificações externas solicitadas pela parceira. Em seguida, é realizada a fase de testes, na qual ocorrem, em paralelo, testes de requisitos que verificam se as funcionalidades estão de acordo com os requisitos iniciais, e os testes de bugs já conhecidos de outras versões do software ou de outros modelos de dispositivo.

A etapa seguinte consiste nos testes de compatibilidade, 


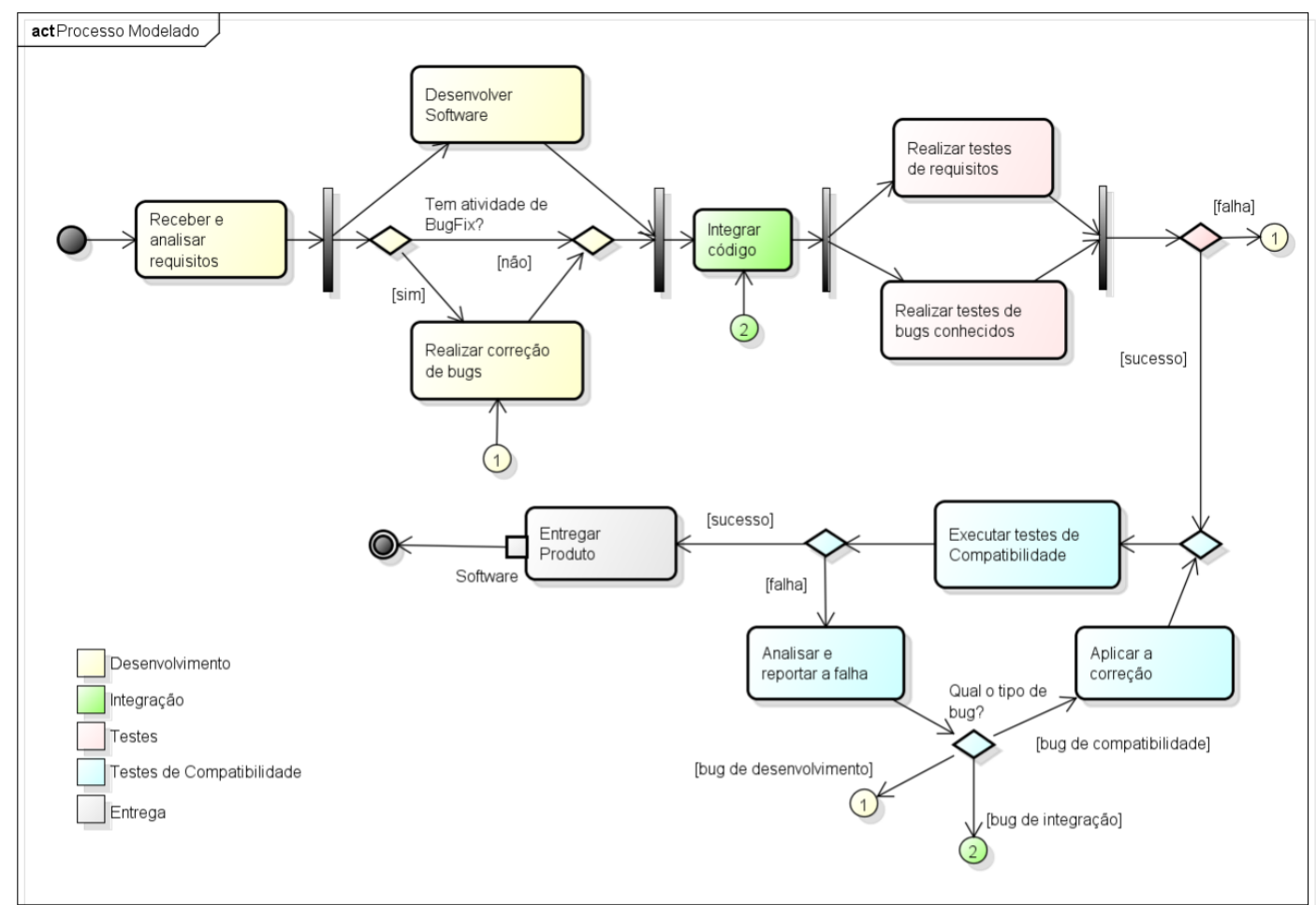

Figura 3: Versão simplificada do processo modelado

que estão relacionados à compatibilidade do código gerado com códigos já existentes. Os tipos de bug encontrados nesta etapa são: bug de desenvolvimento, cuja falha pode ser corrigida pelo analista de sistemas responsável; bug de integração, cuja falha pode ser corrigida pelo time de Integração; e bug de compatibilidade, que pode ser uma falha no código identificado pela parceira ou um problema gerado em alguma das etapas anteriores. Todos os bugs devem ser analisados e reportados para que sejam corrigidos o mais rápido possível.

Por fim, na etapa de entrega do produto, o software produzido é configurado de acordo com as solicitações da parceira e os artefatos que serão entregues são colocados em seus respectivos repositórios. Esses artefatos consistem não somente nos arquivos de código-fonte do software, mas também nos resultados de testes e outras documentações.

\subsection{Utilização do processo}

Com relação ao uso do processo, como pode ser observado na figura 4, a equipe, em grande maioria, acredita utilizar corretamente o processo e que ele está disponível a todos.

A partir das análises qualitativas, alguns comentários se destacaram, pois foram recorrentes em várias entrevistas. Dentre eles estão: "antes do último gerente não tinha um processo bem definido", "a equipe não seguia um processo", "o gerente organizou melhor o processo e incentivou a união da equipe", "a utilização de ferramentas como o quadro Kanban simplificou o processo". Vê-se, pois, que a entrada de um gerente de projeto com uma perspectiva mais focada no processo alterou como a equipe enxerga o processo e o aplica.

Em outro momento, foram perguntados quais os benefícios de se ter um processo bem definido e documentado. As respostas mais recorrentes foram ligadas ao reconhecimento dos papeis e de suas importâncias, à melhor organização dos
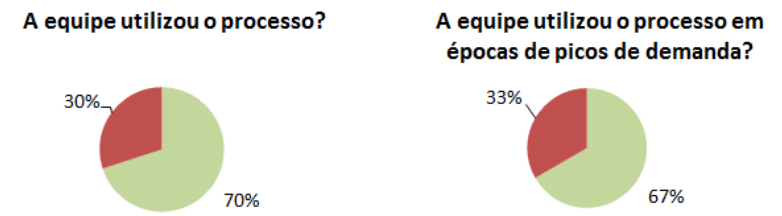

Você utiliza o processo corretamente?

O processo está documentado $\mathrm{e}$ acessível?
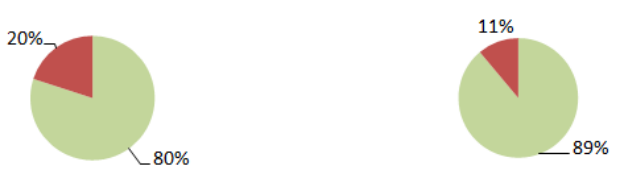

Sim $\square$ Não

Figura 4: Utilização do processo

prazos para negociar com a empresa parceira, à identificação de falhas, à melhor comunicação dentro da equipe (permitindo que os integrantes identifiquem melhor cada fase do processo), e à produção de um melhor produto final.

Indagados sobre algum motivo que faça a equipe não conhecer ou seguir o processo, um deles afirmou que:

"Geralmente quem atrasava era porque não estava entendendo o processo. Eu imagino isso, porque ele não tem noção do impacto que isso vai trazer para o processo."

A equipe também deixou claro que identificar falhas não tem o objetivo de apontar um culpado, mas sim de enten- 
der qual parte do processo não foi executada corretamente. Além disso, alguns entrevistados afirmaram que é necessário que a equipe conheça seus limites a fim de planejar melhor sua carga de trabalho.

\subsection{Documentação}

A documentação do projeto era organizada na plataforma colaborativa Confluence. Neste caso, cada time era responsável pela sua própria documentação.

Nesse tópico, os resultados apresentados mostram uma certa contradição quanto às respostas para as perguntas "Você utilizava a documentação?" e "A equipe utilizava a documentação?". Isso se dá porque todos os entrevistados responderam sim para a primeira pergunta, mas metade dos entrevistados responderam não para a segunda pergunta.

Um dos entrevistados afirmou que "a documentação é um mal necessário", outro que o "processo era complexo e a documentação não era suficiente". Estes pontos demonstram uma resistência de alguns membros da equipe à utilização da documentação para conhecimento do processo. Por fim, pôde-se perceber que a equipe julga a documentação importante, apesar de afirmar várias vezes que não a acessa frequentemente.

Quando questionados sobre como aprenderam o processo, $80 \%$ do grupo afirmou que aprendeu o processo na prática, enquanto o restante dos entrevistados afirmou que aprendeu tanto na prática quanto com auxílio de documentação. Ninguém afirmou ter aprendido somente com documentação.

\subsection{Ferramentas}

A equipe utiliza várias ferramentas para auxiliar o trabalho. Dentre elas estão ferramentas de comunicação, organização de tempo, rastreamento de bugs, organização da documentação e realização de tarefas com a parceira. As ferramentas mais citadas foram Confluence, utilizada para documentação, e $\mathrm{Jira}^{4}$, utilizada para acompanhamento das atividades e rastreamento de bugs.

Observou-se, através das perguntas "a equipe utiliza bem as ferramentas?" e "Você se sente confortável em utilizar essas ferramentas?" que $86 \%$ da equipe não acredita que usa bem as ferramentas, embora $86 \%$ tenha afirmado que se sente confortável em utilizá-las.

De acordo com os comentários sobre a ferramenta Jira, percebeu-se que a equipe não possui a "cultura" (palavra usada por muitos deles) de utilizá-la. Outras hipóteses foram levantadas para a não utilização correta das ferramentas, entre elas estão a complexidade das ferramentas e a burocratização do sistema.

Em uma afirmação sobre o uso de ferramentas em projetos de software, um dos entrevistados explicou que os desenvolvedores possuem uma rejeição ao fazer algo fora do ambiente de programação de software. Já outros afirmaram que não possuem tempo suficiente para se dedicar à ferramenta.

Além disso, foram apontados muitos benefícios em se utilizar ferramentas: ter documentação disponível, ter histórico para trabalhar com medidas de qualidade, controle das atividades, análise visual da demanda e prazos.

Por fim, o Quadro Kanban foi uma das ferramentas frequentemente citadas. Esse quadro é uma lousa adaptada às etapas do processo onde é possível que todos interajam fisicamente através da movimentação de post-its que representam uma atividade do projeto. A lousa, inspirada na

\footnotetext{
${ }^{4}$ https://www.atlassian.com/software/jira
}

pesquisa desenvolvida por Sousa et. al. [20], apresentou sucesso na sua utilização e na aceitação da equipe. Apesar de a ferramenta Jira poder ser utilizada para a mesma finalidade, a equipe expressou que, para utilizar o Jira, seria necessário implementar as regras de negócio na ferramenta e que isso aumentaria a complexidade da ferramenta. Além disso, eles afirmaram que o ato de movimentar os post-its chama a atenção da equipe, que normalmente está focada em seus computadores.

\section{LIÇÕES APRENDIDAS}

Durante a modelagem do processo, diversas lições foram identificadas. Das lições aprendidas podemos citar:

- Fazer um teste piloto do roteiro da entrevista. Realizar um teste piloto do roteiro de entrevista apontaria algumas melhorias que só foram verificadas após a execução de várias entrevistas. Apesar da entrevista ser flexível com um roteiro semiestruturado, melhorias não puderam ser aplicadas durante a execução das entrevistas para não invalidar a comparação dos dados;

- A gravação e transcrição são importantes para rever os dados. Gravar e transcrever as entrevistas foi um excelente método para registro dos dados. Isso porque somente com as anotações não seria possível colher tantos dados e voltar a eles quando necessário;

- Permitir que o entrevistado desenhasse o processo deu maior flexibilidade e clareza para expressar sua opinião. Trazer a modelagem da versão anterior do processo impressa para os entrevistados rabiscarem suas próprias conclusões e correções foi uma boa forma para entender como o processo realmente funciona na perspectiva do entrevistado;

- Apoio da gerência. Ter a disponibilidade e apoio dos gerentes e líderes foi essencial para realização da pesquisa, pois eles permitiram que as entrevistas fossem realizadas no horário de trabalho e disponibilizaram dados internos do projeto. Isto forneceu o insumo inicial para a pesquisa.

- A participação da equipe faz com que eles tenham maior confiança no processo modelado. Fazer a modelagem do processo com base na percepção de todos os cargos da equipe deu maior confiabilidade ao resultado final, pois cada participante pôde conhecer os detalhes das atividades de todos da equipe. Além disso, como os gerentes e líderes técnicos possuíam visões em um nível mais abstrato sobre as atividades, isso poderia causar a omissão de algum detalhe importante na modelagem que poderia ser, então, indicado por um analista de desenvolvimento, por exemplo.

\section{CONSIDERAÇÕES FINAIS}

Este artigo apresentou um relato de experiência da modelagem interativa de um processo de software em um projeto de P\&D\&I. O diferencial desta modelagem interativa foi a participação de toda a equipe do projeto durante a modelagem do processo de desenvolvimento de software vigente.

Durante o processo de modelagem, foi possível perceber que há divergências de conceito sobre atividades do processo entre os diversos participantes da equipe. Essas divergências 
surgem devido ao conhecimento sobre as atividades, o qual variava entre os membros da equipe. A versão final do processo modelado permitiu que todos os envolvidos tivessem uma visão geral das atividades que eram executadas, bem como auxiliou a integração de novos membros na equipe.

Também foram apresentadas as principais lições aprendidas durante esse processo de modelagem. Uma vez que utilizou-se entrevistas como técnica de coleta de dados, a maioria delas está relacionada às entrevistas realizadas.

Uma vez que o ambiente de execução da experiência descrita nesse artigo foi em projetos reais, acredita-se que os resultados podem apoiar outras equipes de desenvolvimento de software na modelagem do processo utilizado. Além disso, o resultado empírico documentado neste artigo pode ser utilizado por pesquisadores que investigam estudos empíricos na modelagem de processos de desenvolvimento de software.

Como trabalho futuro, pretende-se aplicar essa abordagem em outros projetos e contemplar as lições aprendidas.

\section{ACKNOWLEDGMENTS}

Bruno S. Aragão é bolsista da Fundação Cearense de Pesquisa e Cultura. Rossana M. C. Andrade é bolsista do CNPq de Produtividade em Desenvolvimento Tecnológico e Extensão Inovadora (DT) 2 .

\section{Referências}

[1] S. T. Acuña, A. de Antonio, X. Ferré, M. López, and L. Maté. The Software Process: Modelling, Evaluation and Improvement. Handbook of Software Engineering and Knowledge Engineering, pages 193-237, 2001.

[2] S. D. Barbosa and B. S. Silva. Interação HumanoComputador. Elsevier Brasil, 15th edition, 2010.

[3] R. C. Bogdan and S. K. Biklen. Investigação qualitativa em educação: uma introdução à teoria e aos métodos. 1994.

[4] T. F. Cunha, V. L. Dantas, and R. M. C. Andrade. Sless: A scrum and lean six sigma integration approach for the development of sofware customization for mobile phones. In Software Engineering (SBES), 2011 25th Brazilian Symposium on, pages 283-292, 2011.

[5] J. J. L. Dias Júnior, A. F. P. Belo, and F. N. M. Dias. Percepções sobre um processo de software sob o ponto de vista das equipes de desenvolvimento: Um estudo de caso. In Simpósio Brasileiro de Qualidade de Software, 2014.

[6] J. J. L. Dias Júnior, A. E. da Silva, and F. N. M. Dias. A percepção de uma equipe sobre o processo de gerência de configuração em relação ao mps.br nível f: Um estudo de caso. In Simpósio Brasileiro de Qualidade de Software, 2014.

[7] P. Diebold and S. A. Scherr. Software process models vs. descriptions: What do practitioners use and need? In Proceedings of the International Workshop on Software and Systems Process, ICSSP '16, pages 66-75, New York, NY, USA, 2016. ACM.

[8] A. Fuggetta. Software process: A roadmap. In Proceedings of the Conference on The Future of Software Engineering, ICSE '00, pages 25-34, New York, NY, USA, 2000. ACM.
[9] J. Kožusznik and S. Štolfa. Knowledge Based Approach to Software Development Process Modeling, pages 1628. Springer, Berlin, Heidelberg, 2011.

[10] F. T. Leite. Metodologia Científica: métodos e técnicas de pesquisa: monografias, dissertações, teses e livro. Ideias \& Letras, $3^{\circ}$ edição edition, 2012.

[11] M. B. Miles, M. A. Huberman, and J. Saldaña. Qualitative data analysis: a methods sourcebook, 2014.

[12] R. Moraes. Análise de conteúdo. Revista Educação, 22(37):7-32, 1999.

[13] A. S. Oliveira, A. T. Oliveira, D. S. M. Oliveira, M. P. G. Carneiro, R. L. A. Almeida, and T. G. R. Darin. Exposição de imagem no facebook: um estudo sobre a privacidade na rede social. In Proceedings of the 11th Brazilian Symposium on Human Factors in Computing Systems, IHC '12, pages 69-70, Porto Alegre, Brazil, 2012. Brazilian Computer Society.

[14] R. S. Pressman. Engenharia de software. AMGH Editora, 2009.

[15] Y. Rogers, H. Sharp, and J. Preece. Design de Interação. Bookman Editora, 2013.

[16] K. Schwaber and M. Beedle. Agile Software Development with Scrum. 2001.

[17] C. R. Silva, B. C. Gobbi, and A. A. Simão. O uso da análise de conteúdo como uma ferramenta para a pesquisa qualitativa: descrição e aplicação do método. Organizações Rurais $\&$ Agroindustriais, 7(1), 2011.

[18] SOFTEX. Mps.br - melhoria de processo do software brasileiro. guia geral mps para software:2016, 2016.

[19] I. Sommerville. Engenharia de Software, volume 22. Pearson Addison-Wesley, 2007.

[20] J. N. B. Sousa, A. H. M. T. Monteiro, A. F. Oliveira, F. V. da Silva, I. S. Santos, R. B. Braga, and R. M. C. Andrade. Skam: Um processo usando scrum e kanban para customização de software em dispositivos móveis. In X Workshop Anual do MPS (WAMPS 2014), 2014.

[21] Y. Sugimori, K. Kusunoki, F. Cho, and S. Uchikawa. Toyota production system and kanban system materialization of just-in-time and respect-for-human system. The International Journal of Production Research, 15(6):553-564, 1977.

[22] M. Thiry, C. G. von Wangenheim, A. Zoucas, and K. Pickler. Uma abordagem para a modelagem colaborativa de processos de software em micro e pequenas empresas. In Simpósio Brasileiro de Qualidade de Software, 2006.

[23] D. Xavier, D. Viana, and B. Gadelha. A study on the relationship between process and motivation in software development teams. In Proceedings of the XII Brazilian Symposium on Information Systems, SBSI 2016, pages 11:76-11:83, Porto Alegre, Brazil, 2016. Brazilian Computer Society. 